\title{
Effect of Intensive Interdisciplinary Transitional Care for High-Need, High-Cost Patients on Quality, Outcomes, and Costs: a Quasi-Experimental Study
}

\author{
James E. Bailey, MD ${ }^{1,2,3}$, Satya Surbhi, $P h D^{1,2}$, Jim Y. Wan, PhD ${ }^{1,3}$, Kiraat D. Munshi, PhD , \\ Teresa M. Waters, $P h D^{1,3,5}$, Bonnie L. Binkley, MA ${ }^{1,2}$, Michael O. Ugwueke, $D H A^{6}$, and \\ llana Graetz, $P h D^{1,3,7}$
}

\begin{abstract}
${ }^{1}$ Center for Health System Improvement, University of Tennessee Health Science Center, Memphis, TN, USA; ${ }^{2}$ Department of Medicine, University of Tennessee Health Science Center, Memphis, TN, USA; ${ }^{3}$ Department of Preventive Medicine, University of Tennessee Health Science Center, Memphis, TN, USA; ${ }^{4}$ Express Scripts Holding Company, Memphis, TN, USA; ${ }^{5}$ Department of Health Management and Policy, University of Kentucky College of Public Health, Lexington, KY, USA; ${ }^{6}$ Methodist Le Bonheur Healthcare, Memphis, TN, USA; ${ }^{2}$ Department of Health Policy and Management, Emory University Rollins School of Public Health, Atlanta, GA, USA.
\end{abstract}

BACKGROUND: Many health systems have implemented team-based programs to improve transitions from hospital to home for high-need, high-cost patients. While preliminary outcomes are promising, there is limited evidence regarding the most effective strategies.

OBJECTIVE: To determine the effect of an intensive interdisciplinary transitional care program emphasizing medication adherence and rapid primary care follow-up for high-need, high-cost Medicaid and Medicare patients on quality, outcomes, and costs.

DESIGN: Quasi-experimental study.

PATIENTS: Among 2235 high-need, high-cost Medicare and Medicaid patients identified during an index inpatient hospitalization in a non-profit health care system in a medically underserved area with complete administrative claims data, 285 participants were enrolled in the SafeMed care transition intervention, and 1950 served as concurrent controls.

INTERVENTIONS: The SafeMed team conducted hospitalbased real-time screening, patient engagement, enrollment, enhanced discharge care coordination, and intensive home visits and telephone follow-up for at least 45 days.

MAIN MEASURES: Primary difference-in-differences analyses examined changes in quality (primary care visits, and medication adherence), outcomes (preventable emergency visits and hospitalizations, overall emergency

\footnotetext{
$\overline{\text { Prior Presentation Preliminary results of this study were presented in }}$ abstract form as a poster presentation entitled "Cost Savings Associated with Participation in the Safemed Program, an Innovative Care Transitions Program for Super-Utilizers with Multiple Chronic Conditions" at the Academy Health Annual Research Meeting in Minneapolis, MN, June 15, 2015, by Bailey JE, Graetz I, Munshi KD, Surbhi S, Wan JY, and Waters TM. These preliminary results have been referenced in several subsequent presentations and in SafeMed toolkits (co-branded by the American Medical Association and the Society of General Internal Medicine) available at www.stepsforward.org/modules/safemed-transition-care and at www. SafeMed.org.
}

Electronic supplementary material The online version of this article (https://doi.org/10.1007/s11606-019-05082-8) contains supplementary material, which is available to authorized users.

Received August 2, 2018

Revised January 19, 2019

Accepted April 19, 2019

Published online July 3, 2019 visits, hospitalizations, 30-day readmissions, and hospital days), and medical expenditures.

KEY RESULTS: Adjusted difference-in-differences analyses demonstrated that SafeMed participation was associated with $7 \%$ fewer hospitalizations $(-0.40 ; 95 \%$ confidence interval (CI), -0.73 to -0.06 ), $31 \%$ fewer 30 -day readmissions $(-0.34 ; 95 \% \mathrm{CI},-0.61$ to -0.07$)$, and reduced medical expenditures (\$-8690; 95\% CI, $\mathbf{\$}-14,441$ to $\mathbf{\$}-2939$ ) over 6 months. Improvements were limited to Medicaid patients, who experienced large, statistically significant decreases of $39 \%$ in emergency department visits, $25 \%$ in hospitalizations, and 79\% in 30-day readmissions. Medication adherence was unchanged (+ $2.6 \%$; $95 \% \mathrm{CI},-39.1 \%$ to $72.9 \%$ ).

CONCLUSIONS: Care transition models emphasizing strong interdisciplinary patient engagement and rapid primary care follow-up can enable health systems to improve quality and outcomes while reducing costs among high-need, high-cost Medicaid patients.

KEY WORDS: care transitions; chronic disease; health care delivery; underserved populations; quality improvement; super-utilizer; multiple chronic conditions; Medicaid; Medicare.

J Gen Intern Med 34(9):1815-24

DOI: $10.1007 / \mathrm{s} 11606-019-05082-8$

(c) Society of General Internal Medicine 2019

$\mathrm{N}$ early one quarter of US health care resources are spent on only $1 \%$ of the population, and the majority of these resources are spent on potentially avoidable emergency department (ED) visits, hospitalizations, and readmissions by high-need, high-cost patients. These patients, often referred to as "super-utilizers," are characterized by complex medical and social needs that the fragmented US health care system is ill-prepared to address. ${ }^{1-6}$ Although many approaches have been suggested to reduce potentially unnecessary utilization, interest has particularly focused on improving care transitions from hospital to home. Preliminary research suggests that interdisciplinary care teams conducting repeated follow-up post hospital discharge can help make sure complex patients 
get the care they need most. ${ }^{3,} 7-9$ Care transitions have been identified as a critical time for intervention, since health care costs particularly escalate surrounding hospitalizations related to chronic disease exacerbations..$^{7-12}$ Furthermore, research demonstrates that patients with complex chronic conditions are among those with the highest needs and highest cost. ${ }^{13,14}$ But thus far, there is insufficient evidence regarding the essential components of care transition programs needed to achieve triple aim goals of improved quality and outcomes and reduced costs for high-need, high-cost patients with complex chronic conditions. $^{7-9,11}$

Increasing evidence suggests that effective care transition programs need to be tailored to target specific segments or clinical groups of high-need, high-cost patients with the greatest likelihood of ongoing high utilization. ${ }^{7-9}$ The National Academy of Medicine, the Commonwealth Fund, and the National Center for Complex Health and Social Needs have provided extensive guidance on promising approaches for targeting and meeting the medical and social needs of highneed, high-cost patients. ${ }^{6,8,9}$ Recent systematic reviews conclude that key attributes of effective care models for highneed, high-cost patients include careful patient targeting during transitions, home visits, rapid outpatient follow-up, and ongoing multidisciplinary outreach emphasizing medication management. ${ }^{8,9,12}$ However, despite the substantial evidence that medication non-adherence contributes to high utilization, ${ }^{15-19}$ most care transition programs have not made medication management a primary focus. ${ }^{6}, 15,20,21$ Evidence suggests that hospital-based medication management interventions during care transitions can reduce drug therapy problems ${ }^{22-25}$ but they are not sufficient to reduce readmissions. ${ }^{22}$

We investigated the effects of an innovative care transition model - SafeMed — on health care quality, medical costs, and utilization in high-need Medicaid, Medicare, and dual-eligible patients. The SafeMed model differs from earlier care transition models ${ }^{26-28}$ by focusing explicitly on the highest utilizers of inpatient and emergency services rather than all hospitalized patients and emphasizing intensive patient engagement and proven medication therapy management approaches. ${ }^{22,}$ 29-31 We examined quality, outcomes, and medical expenditures from 2013 to 2015 to assess whether intensive interdisciplinary transitional care for high-need, high-cost patients can help health systems simultaneously improve quality and outcomes while reducing costs.

\section{METHODS}

\section{Setting}

The Centers for Medicare and Medicaid Services Health Care Innovations Award-funded SafeMed program was implemented in three hospitals including one academically affiliated university hospital and two community hospitals within a large non-profit health care system (Methodist Le Bonheur Healthcare) with a total of five adult hospitals and one major academic children's hospital. The three participating hospitals are the largest hospitals serving the major medically underserved areas ${ }^{32}$ and geographic hotspots for readmissions of Memphis, Tennessee. ${ }^{33}$

\section{Data Sources}

Real-time health system electronic medical record (EMR) data was used for participant identification, recruitment, and enrollment. Patient-level Medicare and Medicaid administrative claims data were used for the assessment of all study outcomes.

For Medicare beneficiaries, the study used Chronic Conditions Data Warehouse files including pharmacy and medical claims for all fee-for-service Medicare beneficiaries with part A, B, and D coverage. Data on hospitalizations were obtained using Medicare Provider Analysis and Review files. Data on observation stays and ED visits were obtained using Medicare outpatient revenue center files. Part D drug event files were used to assess medication adherence, and diagnosis codes present in the inpatient, outpatient, or part B claims were used to assess chronic conditions. Medicare beneficiary summary files (A, B, and D) were used to assess demographic factors.

Comparable Tennessee Medicaid (TennCare) eligibility, professional, inpatient, outpatient, and pharmacy administrative claims files were used for patients with Medicaid coverage.

\section{Intervention}

The SafeMed care transition model emphasizes early identification and patient engagement in the hospital followed by intensive community-based follow-up for a minimum of 45 days after hospital discharge. ${ }^{30,34,35}$ Key multidisciplinary SafeMed team members included one advanced practice nurse, one registered nurse, two pharmacists, one social worker, two licensed practical nurses (LPNs), and two certified pharmacy technicians (CPhTs). Key hospital-based SafeMed interventions included (1) real-time screening and enrollment of eligible patients by lead nurses, (2) patient engagement (i.e., building relationship and rapport) by all SafeMed staff, (3) medication reconciliation and medication therapy management (MTM) led by program pharmacists, and (4) enhanced discharge preparation (i.e., planning, scheduling follow-up appointments, education, and care coordination) by all SafeMed staff. SafeMed personnel and regular hospital personnel worked separately and in parallel to avoid contamination between groups. SafeMed personnel only provided extra services (above usual care) to patients enrolled in SafeMed. Key community-based interventions included weekly telephone follow-up and biweekly home visits starting immediately post discharge by low-cost two-person LPN/CPhT teams accompanied by a social worker on an as-needed basis. These community health worker teams used standardized tools and protocols for chronic disease assessment, medication reconciliation, care coordination, MTM, and identifying and addressing social needs at regular visits. ${ }^{30,34,35}$ 


\section{Study Population}

Potential participants were assessed for basic eligibility criteria in real-time using health system EMR data (see Fig. 1, Enrollment). We identified all patients meeting the following basic inclusion criteria: (1) current index hospitalization or observation stay between February 1, 2013, and May 1, 2015, in a participating hospital; (2) age > 18 years; (3) current Medicare, Medicaid, or dual-eligibility; (4) residence in ZIP codes identified as medically underserved and readmission hotspots 32,33 (5) $\geq 2$ inpatient admissions or one inpatient admission and $\geq 2$ ED visits in the 6 months prior to the index hospitalization at any of the five adult hospitals in the health system; and (6) diagnosis of $\geq 1$ ambulatory care-sensitive chronic conditions (Appendix Table 1). ${ }^{36,37}$ Patients were excluded for selected complex conditions for which the health system either had alternative care pathways or was under-resourced to address effectively at the time of the study including recent diagnosis of psychosis, suicidal ideation, or substance abuse; homelessness; discharge to a location other than home; or if the primary reason for index hospitalization was related to cancer, pregnancy, or a surgical procedure for an acute problem. We used the International Classification of Diseases, Ninth Revision, Clinical Modification (ICD-9-CM) codes and diagnosisrelated group (DRG) codes used by Harris and colleagues for inclusion and exclusion criteria. ${ }^{31}$ Patients with dementia (ICD-9-CM codes 290.x, 294.10-11, 294.20-21, 331.0-2) were also excluded unless they had a competent caregiver who agreed to assist. ${ }^{34,35}$

Participants were allocated to the intervention group who were able to be screened and consented and who agreed to be enrolled in the SafeMed program (see Fig. 1, Allocation). During screening, SafeMed staff confirmed that a targeted ambulatory care-sensitive chronic condition contributed to the index admission and patient use of six or more medications

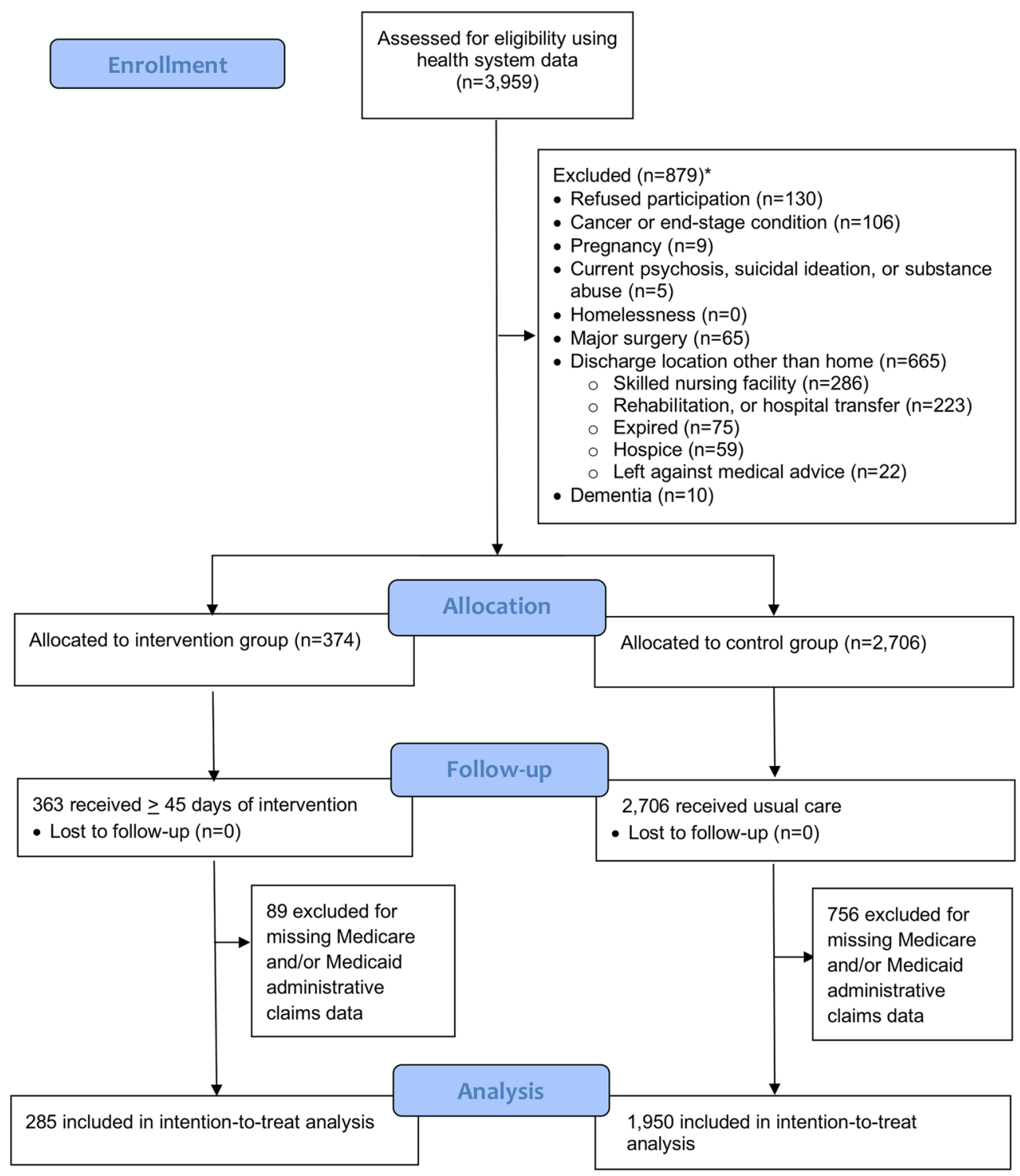

Fig. 1 SafeMed Consolidated Standards of Reporting Trials (CONSORT) flow diagram. 
or a high-risk medication. ${ }^{34,}{ }^{35}$ Staff also used EMR data to screen patients in real time for primary exclusion criteria listed above and additional screening questions to exclude patients with an end-stage condition (life expectancy of $\leq 6$ months) or repeated history of illicit drug use in the past 6 months.

Concurrent controls included patients meeting program eligibility criteria above at index hospitalization, but who were discharged before enrollment or who were otherwise unable to be enrolled during their index hospitalization $(n=2706)$. Eligibility was confirmed for all intervention and control subjects using an algorithm employing Medicare and Medicaid data (Appendix 1). Only patients with complete Medicare and/or Medicaid data from February 1, 2013, through May 1, 2015, were included in the final intention to treat analysis (see Fig. 1, Follow-up and Analysis).

\section{Study Design}

We used a difference-in-differences (DID) analysis to compare quality, outcomes, and costs for participants and controls. Each individual was followed for a baseline period of 6 months prior to index hospital admission date and an intervention period of 6 months following discharge date. We assessed program impact on the pre-specified outcomes of primary care physician (PCP) visits, preventable and overall hospitalizations and ED visits, 30-day readmissions, and medical expenditures for the overall population and the Medicare, Medicaid, and dual-eligible subgroups. The study was approved by the University of Tennessee Health Science Center Institutional Review Board (no. 12-02232-XM).

\section{Study Variables}

Quality, Outcomes, and Expenditures. Because there is overlap between quality and outcome measures, we followed National Quality Forum standards to classify each measure as either quality or outcome. ${ }^{38}$ We measured quality of care by assessing overall PCP visits, $\geq 1$ PCP visits within 14 days of index hospital discharge, and medication adherence (using the proportion of days covered (PDC) for all chronic disease medications with $\mathrm{PDC} \geq 80 \%$ defined as adherent). ${ }^{39} \mathrm{We}$ measured patient health outcomes by numbers of preventable ED visits and hospitalizations, ${ }^{40}$ overall ED visits and hospitalizations, 30-day readmissions, and hospital days. Readmissions were assessed by summing the total number of unique hospitalizations occurring within 30 days of a prior hospital discharge in the period. ${ }^{41}$ Medical expenditures included the sum of all Medicare and Medicaid payments (paid claims) but not out-of-pocket amounts (Appendix 2).

Independent Variables. Primary independent variables were binary indicators of whether patients received the SafeMed intervention (participant, control) and study period (pre, post). Covariates included baseline age in years, gender, and race/ ethnicity (non-Hispanic whites/others, non-Hispanic blacks) from Medicare Beneficiary Summary files and Medicaid eligibility files; baseline insurance status (Medicare only, Medicaid only, or dual-eligible) $;{ }^{42}$ baseline and intervention 6-month period diagnoses of depression or anxiety, tobacco use disorder, and end-stage renal disease; and baseline and intervention period Charlson Comorbidity Index. ${ }^{43}$

\section{Statistical Analysis}

We used DID analysis to estimate the average pre-post change in quality of care, health outcomes, and costs of care for SafeMed participants compared to controls. Negative binomial regression models were used for preventable hospitalizations, preventable ED visits, and all health care utilization outcomes, while expenditures were analyzed using generalized linear regression models. Additionally, we employed logistic regression and linear probability models to examine whether enrollment in SafeMed was associated with improvements in medication adherence and PCP visits, respectively. We ran all models for the overall population and by subgroup (Medicare, Medicaid, dual). Multivariate analyses controlled for all covariates except for individual chronic conditions since the Charlson Comorbidity Index were used to assess comorbidity. A significance $P$ level of $<0.05$ and 2-sided tests were used for all analyses.

In sensitivity analyses, we reran all models among SafeMed participants and propensity score-matched controls. The variables used to match controls included all covariates measured at baseline. All data analyses were conducted using SAS 9.4 (SAS Institute, Inc., Cary, NC) and Stata 13 (StataCorp 2013, College Station, TX).

\section{KEY RESULTS}

\section{Study Population}

Of 504 patients offered SafeMed participation, 374 (74.2\%) agreed to participate, and $285(76.2 \%)$ were found to have continuous Medicare, Medicaid, and/or dual-eligible coverage for the study period. Our analyses included these 285 intervention patients, along with 1950 concurrent program-eligible controls with complete Medicare and/or Medicaid administrative claims data from February 1, 2013, through May 1, 2015 (Fig. 1). As shown in Table 1, SafeMed (intervention) and control group patients were similar with regard to gender, Charlson Comorbidity Index, and the number of unique medications but differed with regard to age, race, and insurance coverage. In addition, the SafeMed-enrolled patients experienced significantly higher rates of diabetes, congestive heart failure, coronary artery disease, asthma, and COPD and significantly lower rates of end-stage renal disease.

Furthermore, we found significant heterogeneity among SafeMed-eligible patients (intervention and controls) by insurance type (Appendix Table 2). As expected, Medicare patients were significantly older than both Medicaid and dual-eligible patients and had higher rates of comorbidity. Medicaid 
Table 1 Baseline Characteristics Among SafeMed Participants and Controls

\begin{tabular}{|c|c|c|c|}
\hline Characteristics & $\begin{array}{l}\text { SafeMed participants } \\
(N=\mathbf{2 8 5})\end{array}$ & $\begin{array}{l}\text { Program-eligible controls } \\
(N=1950)\end{array}$ & $\overline{P \text { value }}{ }^{\mathrm{a}}$ \\
\hline Age (mean, SD) & $57.0(15.3)$ & $61.1(16.5)$ & $<0.001$ \\
\hline Female gender $(\%)$ & 60.7 & 56.5 & 0.18 \\
\hline \multicolumn{4}{|l|}{ Race/ethnicity* } \\
\hline Non-Hispanic white & 13.0 & 27.7 & \multirow[t]{3}{*}{$<0.001$} \\
\hline Non-Hispanic black & 75.4 & 64.5 & \\
\hline Other/Hispanic & 11.6 & 7.7 & \\
\hline \multicolumn{4}{|l|}{ Insurance $^{\dagger}$} \\
\hline Medicare only & 21.7 & 30.1 & \multirow[t]{3}{*}{$<0.001$} \\
\hline Medicaid only & 39.3 & 28.3 & \\
\hline Dual-eligible & 40.0 & 41.6 & \\
\hline \multicolumn{4}{|l|}{ Comorbidity } \\
\hline Hypertension & 83.5 & 84.5 & 0.68 \\
\hline Diabetes & 64.2 & 53.9 & 0.001 \\
\hline Congestive heart failure & 64.9 & 53.7 & $<0.001$ \\
\hline Coronary artery disease & 58.9 & 50.4 & 0.007 \\
\hline Asthma & 36.5 & 25.1 & $<0.001$ \\
\hline Chronic obstructive pulmonary disease & 51.9 & 37.1 & $<0.001$ \\
\hline Depression/anxiety & 27.4 & 30.5 & 0.29 \\
\hline Tobacco use disorder & 29.5 & 25.6 & 0.16 \\
\hline End-stage renal disease & 20.1 & 27.5 & 0.01 \\
\hline Charlson Comorbidity Index, mean (SD) & $4.7(2.5)$ & $4.7(2.7)$ & 0.86 \\
\hline Number of unique medications, mean (SD) & $7.2(9.3)$ & $8.1(8.5)$ & 0.12 \\
\hline
\end{tabular}

*A single $P$ value is included for the categorical race and insurance status variables for the comparison of intervention and control patients

'Bivariate comparisons for continuous measures ( $t$ test) and proportions (chi-square test)

${ }^{*}$ Based on the 6-month period prevalence of diagnosis using the International Classification of Diseases, Ninth Revision, Clinical Modification (ICD-9CM) codes

patients had significantly lower rates of primary care visits. Despite higher comorbidity levels among Medicare patients, Medicaid patients had higher baseline rates of preventable and overall ED visits and hospital utilization (Table 2).

\section{Changes in Quality}

After controlling for differences in age, gender, race/ethnicity, insurance, diagnoses of depression or anxiety, tobacco use disorder, end-stage renal disease, and Charlson Comorbidity Index, exposure to the SafeMed intervention was not associated with any changes in medication adherence (Table 3 and Appendix Table 3). However, intervention exposure was associated with increased rates of primary care visits within 14 days of index hospital discharge (6.2\% per 6-month period;
95\% CI, 0.3 to 12.1$)$ and decreased preventable hospitalizations $(-0.10$ per 6 -month period; $95 \% \mathrm{CI},-0.17$ to -0.04$)$, respectively. Subgroup analysis demonstrated that significant decreases were limited to the Medicaid population. Although no significant changes were seen in the number of PCP visits over the entire 6-month intervention period, intervention patients were significantly more likely to have a PCP visit within 14 days of discharge (odds ratio (OR), 1.61; 95\% CI, 1.212.14).

\section{Changes in Outcomes}

In unadjusted DID analyses, SafeMed participants experienced a greater decrease in hospitalizations and 30-day readmissions relative to controls $(7 \%$ and $31 \%$,

Table 2 Baseline 6-Month Period Health Care Utilization and Costs Among SafeMed-Eligible Patients

\begin{tabular}{|c|c|c|c|c|}
\hline Characteristics & $\begin{array}{l}\text { Medicare only } \\
(N=649)\end{array}$ & $\begin{array}{l}\text { Medicaid only } \\
(N=663)\end{array}$ & $\begin{array}{l}\text { Dual-eligible } \\
(N=923)\end{array}$ & $\begin{array}{l}P \text { value for } \\
\text { comparisons }\end{array}$ \\
\hline \multicolumn{5}{|l|}{ Baseline utilization, mean (SD) } \\
\hline Medication adherence $\geq 80 \%(\%)^{\dagger}$ & 46.8 & 27.3 & 38.9 & $1,2,3$ \\
\hline Primary care visits & $7.5(5.6)$ & $4.3(6.3)$ & $7.5(6.7)$ & 1,2 \\
\hline$\geq 1$ primary care visit within 14 days of discharge $(\%)$ & 51.0 & 14.0 & 49.4 & 1,2 \\
\hline Preventable emergency visits & $0.1(0.4)$ & $0.5(1.2)$ & $0.2(0.8)$ & $1,2,3$ \\
\hline Preventable hospitalizations & $0.5(0.8)$ & $0.7(1.3)$ & $0.6(1.1)$ & 1,3 \\
\hline Emergency visits & $0.9(1.4)$ & $3.4(4.2)$ & $1.8(3.6)$ & $1,2,3$ \\
\hline Hospitalizations & $3.0(0.5)$ & $3.3(1.8)$ & $3.3(1.4)$ & 1,3 \\
\hline 30-day readmissions & $1.1(0.8)$ & $1.4(1.9)$ & $1.2(1.3)$ & 1,2 \\
\hline Hospital days & $15.8(12.0)$ & $13.3(15.6)$ & $16.8(15.5)$ & 1,2 \\
\hline \multicolumn{5}{|l|}{ Baseline cost, mean (SD) } \\
\hline Medical expenditures (\$) & $39,950(25,709)$ & $31,308(32,667)$ & $41,710(33,345)$ & 1,2 \\
\hline
\end{tabular}

*Numbers indicate statistical significance for bivariate analyses employing the chi-square test and t test for categorical and continuous variables, respectively, for the following comparisons: (1) between Medicare only and Medicaid only patients $(P<0.05)$, (2) between Medicaid only and dualeligible patients $(P<0.05)$, or (3) between Medicare only and dual-eligible patients $(P<0.05)$

${ }^{\top}$ Measured in a subsample with available pharmacy claims and continuous enrollment in Medicare part D and/or Medicaid (Medicare $=235$, Medicaid $=396$, dual-eligible $=491$ ) using adherent defined as a proportion of days covered $\geq 80 \% 39$ 
Table 3 Changes in Quality and Outcomes in SafeMed Intervention and Control Groups

\begin{tabular}{|c|c|c|c|c|c|c|}
\hline \multirow[t]{2}{*}{ Measure } & \multicolumn{2}{|c|}{$\begin{array}{l}\text { SafeMed participants, mean } \\
\text { (SD) }(N=\mathbf{2 8 5})\end{array}$} & \multicolumn{2}{|c|}{$\begin{array}{l}\text { Program-eligible controls, } \\
\text { mean }(\mathrm{SD})(N=1950)\end{array}$} & \multirow[t]{2}{*}{$\begin{array}{l}\text { Adjusted difference (DID) } \\
\text { SafeMed vs. controls* }\end{array}$} & \multirow[t]{2}{*}{$P$ value } \\
\hline & Pre-period & Post-period & Pre-period & Post-period & & \\
\hline \multirow{2}{*}{\multicolumn{7}{|c|}{$\begin{array}{l}\text { Quality } \\
>1 \text { nrimary } \text { are visit within } 14 \text { dave of discharoe }(\%)^{*}\end{array}$}} \\
\hline & \multicolumn{5}{|c|}{$\geq 1$ primary care visit within 14 days of discharge $(\%)^{+}$} & \\
\hline Overall & 37.0 & 53.0 & 40.1 & 49.1 & $6.2(0.3$ to 12.1$)$ & 0.04 \\
\hline Medicaid only & 19.2 & 39.3 & 12.9 & 23.6 & $9.8(0.4$ to 19.3$)$ & 0.04 \\
\hline \multicolumn{7}{|c|}{ Medication adherence $\geq 80 \%(\%)^{\S}$} \\
\hline Overall & 28.3 & 21.7 & 37.7 & 29.6 & $2.6(-39.1$ to 72.9$)$ & 0.92 \\
\hline Medicaid only & 26.6 & 15.2 & 27.4 & 18.9 & $-19.4(-64.5$ to 83.0$)$ & 0.61 \\
\hline \multicolumn{7}{|c|}{ Outcomes } \\
\hline \multicolumn{7}{|c|}{ Preventable emergency visits (no.) } \\
\hline Overall & $0.7(1.4)$ & $0.5(1.2)$ & $0.2(0.7)$ & $0.2(0.8)$ & $-0.03(-0.08$ to 0.02$)$ & 0.19 \\
\hline Medicaid only & $1.1(1.8)$ & $0.6(1.2)$ & $0.3(1.0)$ & $0.3(1.2)$ & $-0.08(-0.29$ to 0.13$)$ & 0.43 \\
\hline \multicolumn{7}{|c|}{ Preventable hospitalizations (no.) } \\
\hline Overall & $1.5(1.8)$ & $1.2(1.5)$ & $0.5(0.9)$ & $0.5(1.0)$ & $-0.10(-0.17$ to -0.04$)$ & 0.002 \\
\hline Medicaid only & $1.6(2.1)$ & 0.9 (1.4) & $0.5(1.1)$ & $0.5(1.3)$ & $-0.28(-0.53$ to -0.02$)$ & 0.03 \\
\hline \multicolumn{7}{|c|}{ Emergency visits (no.) } \\
\hline Overall & $2.5(3.1)$ & $1.9(3.0)$ & $1.9(3.5)$ & $1.9(4.2)$ & $-0.34(-0.88$ to 0.01$)$ & 0.06 \\
\hline Medicaid only & $4.0(3.5)$ & $2.8(3.6)$ & $3.2(4.3)$ & $3.5(5.9)$ & $-1.96(-1.82$ to -0.11$)$ & 0.03 \\
\hline \multicolumn{7}{|c|}{ Hospitalizations (no.) } \\
\hline Overall & $3.4(2.5)$ & $2.1(2.5)$ & $3.2(1.1)$ & $2.2(2.7)$ & $-0.40(-0.73$ to -0.06$)$ & 0.02 \\
\hline Medicaid only & $3.7(3.2)$ & $2.3(3.0)$ & $3.2(1.4)$ & $2.8(3.8)$ & $-1.27(-1.98$ to -0.56$)$ & $<0.001$ \\
\hline \multicolumn{7}{|c|}{ 30-day readmissions (no.) } \\
\hline Overall & $1.4(2.4)$ & $1.2(2.1)$ & $1.2(1.2)$ & $1.4(2.5)$ & $-0.34(-0.61$ to -0.07$)$ & 0.01 \\
\hline Medicaid only & $1.8(3.2)$ & $1.5(2.6)$ & $1.3(1.4)$ & $2.1(3.6)$ & $-1.16(-1.85$ to -0.47$)$ & 0.001 \\
\hline \multicolumn{7}{|l|}{ Hospital days (no.) } \\
\hline Overall & $13.0(14.6)$ & 9.5 (17.6) & $15.7(14.7)$ & $12.3(24.1)$ & $-2.20(-5.18$ to 0.77$)$ & 0.15 \\
\hline Medicaid only & $12.4(16.1)$ & $8.0(17.6)$ & $13.5(15.5)$ & $13.3(34.9)$ & $-10.90(-17.51$ to -4.29$)$ & 0.001 \\
\hline
\end{tabular}

*Multivariate difference-in-differences models were adjusted for age, race, gender, and insurance, end-stage renal disease, anxiety/depression, substance abuse, and Charlson Comorbidity Index

'Statistical significance at a $P$ value $<0.05$

${ }^{*}$ The average utilization of $\geq 1$ primary care visit within 14 days of each hospital discharge in the pre-period was compared with the utilization of $\geq 1$ primary care visit within 14 days of the index discharge

${ }^{\xi}$ Medication adherence was measured in a sample of the overall population with available pharmacy claims data and continuous enrollment in Medicare part D and/or Tennessee Medicaid (overall sample: SafeMed participants, N=152; controls, N=970; Medicaid sample: SafeMed participants, $N=79$; controls, $N=317$ ) using the proportion of days covered (PDC), with $P D C \geq 80 \%$ defined as adherent ${ }^{39}$

respectively). Improvements were limited to Medicaid enrollees participating in SafeMed who experienced large, statistically significant decreases of $39 \%$ in ED visits, $25 \%$ in hospitalizations, and $79 \%$ in 30-day readmissions. Results from the adjusted DID analyses show that in the 6-month period after enrolling, SafeMed enrollees had fewer hospitalizations (0.40) and 30-day readmissions (0.34) relative to controls (Table 3). Subgroup analyses demonstrated that the effects of the intervention were limited to the Medicaid enrollees for whom exposure was associated with fewer ED visits, hospitalizations, and 30-day readmissions (1.96, 1.27, and 1.16, respectively).
Intervention exposure was not associated with decreased hospital days in the entire intervention population, but Medicaid enrollees had 7.6 fewer hospital days relative to Medicaid beneficiaries in the control group (Table 3 and Appendix Table 3).

\section{Changes in Expenditures}

Intervention exposure was associated with decreased medical expenditures (\$-8690 per 6-month period; 95\% CI, $-14,441$ to -2939 ) (Table 4). Subgroup analysis revealed that this

Table 4 Change in Medical Expenditures in the SafeMed Intervention and Control Groups

\begin{tabular}{|c|c|c|c|c|c|c|}
\hline \multirow[t]{2}{*}{ Measure } & \multicolumn{2}{|c|}{$\begin{array}{l}\text { SafeMed participants, mean (SD) } \\
(N=285)\end{array}$} & \multicolumn{2}{|c|}{$\begin{array}{l}\text { Program-eligible controls, mean } \\
\text { (SD) }(N=2043)\end{array}$} & \multirow[t]{2}{*}{$\begin{array}{l}\text { Adjusted difference (DID) } \\
\text { SafeMed vs. controls* }\end{array}$} & \multirow[t]{2}{*}{$P$ value } \\
\hline & Pre-period & Post-period & Pre-period & Post-period & & \\
\hline $\begin{array}{l}\text { Total medical } \\
\text { expenditures }(\$)\end{array}$ & $34,220(34,711)$ & $27,628(38,651)$ & $38,682(30,872)$ & $35,256(38,671)$ & $-8690(-14,441$ to -2939$)$ & 0.003 \\
\hline $\begin{array}{l}\text { Total Medicaid only } \\
\text { expenditures }{ }^{*}(\$)\end{array}$ & $31,554(34,291)$ & $21,769(27,019)$ & $31,258(32,359)$ & $31,625(38,255)$ & $-15,998(-24,427$ to -7568$)$ & $<0.001$ \\
\hline
\end{tabular}

*Multivariate difference-in-differences models were adjusted for age, race, gender, and insurance, end-stage renal disease, anxiety/depression, substance abuse, and Charlson Comorbidity Index

Statistical significance at a $P$ value $<0.05$

${ }^{7}$ Sample, $N=1326$ 
decrease was again limited to the Medicaid subgroup, who experienced an adjusted average decrease of $\$-15,998$ (95\% CI, $-24,427$ to -7568 ) (Table 4 and Appendix Table 4).

\section{Sensitivity Analyses}

We used propensity score matching (PSM) on age, gender, race, insurance, Charlson Comorbidity Index, and baseline diagnosis of qualifying chronic conditions, tobacco use disorder, end-stage renal disease, and anxiety/depression to further match controls. Overall and payer subgroup results using PSM were similar to main analyses in significance and direction (Appendix Tables 5, 6, and 7).

\section{DISCUSSION}

Despite longstanding interest in targeting high-need, highcost patients for intensive interdisciplinary care transition support, ${ }^{3,5-7}$ our study is among the first to demonstrate simultaneous improvements in quality, outcomes, and costs for this population. The SafeMed intervention was associated with an overall $7 \%$ decline in hospitalizations and $31 \%$ decrease in 30-day readmissions. These improvements were limited to vulnerable Medicaid patients for whom targeted, intensive, interdisciplinary transitional care was associated with decreases of $39 \%$ in ED visits, $25 \%$ in hospitalizations, and $79 \%$ in 30-day readmissions. We hypothesized a priori that the SafeMed care transition model would lead to greatest improvements in 30-day readmission rates. The SafeMed intervention was particularly intensive during the index hospitalization and in the 45-day period immediately following discharge, the highest risk period for readmission. Intense patient preparation for hospital discharge likely facilitated SafeMed's strong effects on readmissions.

Earlier research has demonstrated that care transition programs and integrated care models can reduce hospital readmissions, but these studies generally focused on less medically and socially complex patients. ${ }^{15}, 20,21,26-28,44$, ${ }^{45}$ Early care transition models, like Boost, ${ }^{26}$ Bridge,$^{27}$ and $\mathrm{RED}^{28}$ which focused on improving coordination of care for all hospitalized patients, generally did not demonstrate simultaneous improvements in quality, outcomes, and costs. Similarly, the care transition models with the strongest evidence of improved quality and outcomes and reduced costs, i.e., the Coleman Care Transitions Program, ${ }^{15,20}$ the Naylor Transitional Care Model, ${ }^{21,} 44$ and the GRACE Model, ${ }^{45}$ were community-based. However, these models focused on other clinical groups of high-need, high-cost patients - namely frail older adults with chronic conditions.

The SafeMed care transition model is unusual in explicitly targeting highest-risk super-utilizers and rigorously demonstrating simultaneous improvements in quality, outcomes, and costs. While the IMPaCT study similarly targeted low-socioeconomic status inpatients and did show some improvements in quality and outcomes, no overall cost reductions were achieved. ${ }^{46}$ Other notable care transition or integrated care programs focused on super-utilizers, such as Health Quality Partners ${ }^{47}$ and Care Management Plus, ${ }^{48}$ did not include younger Medicaid patients with complex chronic conditions, nor did they demonstrate overall cost-savings. Only the Camden Coalition care transition model ${ }^{5,6}$ and Denver Health's integrated care program $^{49}$ explicitly targeted super-utilizing patients with complex chronic conditions. But to our knowledge, only Denver Health's recently reported quasi-experimental study has demonstrated significant improvements in costs and outcomes of care for this population.

This study provides clues as to why SafeMed's core interventions were particularly effective for high-risk Medicaid patients. Although Medicaid participants had lower baseline comorbidity compared to Medicare beneficiaries, they experienced twice as many emergency visits and less than half the number of primary care visits during the baseline period. Thus, Medicaid participants with poor access to and/or engagement in primary care were more likely to benefit from SafeMed's emphasis on rapid primary care follow-up. Our previous study showed that ED visitors with complex chronic conditions from the same medically underserved hotspot communities frequently experience low literacy, unstable employment, housing instability, and behavioral needs that interfere with appropriate outpatient disease management. ${ }^{50}$ SafeMed significantly increased the percentage of highneed, high-cost Medicaid patients seeing a PCP in the critical period immediately following hospital discharge. For these patients, prompt PCP follow-up ${ }^{22,30,34,35}$ may have been critical to reducing readmissions, hospitalizations, ED visits, and costs.

To our knowledge, we are among the first to demonstrate significant reductions in ED utilization in a superutilizing Medicaid population with high baseline ED use. ${ }^{51}$ Our findings are consistent with North Carolina's Medicaid experience where outpatient follow-up visits were beneficial only for Medicaid enrollees with the highest risk of readmissions. ${ }^{52}$ Thus, our study provides strong confirmatory evidence that care transition programs targeting Medicaid super-utilizers should employ intensive interdisciplinary patient engagement emphasizing rapid primary care follow-up.

Our null finding on medication adherence is also important. Although studies have shown that hospital-based medication reconciliation and medication therapy management are not sufficient to reduce readmissions, ${ }^{22}$ we thought that extending these efforts into the home would strengthen their effect. ${ }^{30,34,} 35$ Despite evidence that SafeMed reduced drug therapy problems, ${ }^{34}$ we saw no significant improvements in overall medication adherence. Anecdotal reports from program staff and patients indicate that the primary reason was out-of-pocket costs. Patients 
with very limited income were unable to afford multiple co-pays for chronic disease medications. SafeMed patients reported going to the ED precisely to get free short courses of medication therapy for repeated exacerbations of chronic conditions. This finding is consistent with research indicating that even small medication co-pays can present major barriers to adherence for low-income patients with multiple chronic conditions. ${ }^{53,54}$

The substantial reductions in medical expenditures experienced by high-need, high-cost patients participating in SafeMed indicate that the model could produce significant returns on investment. Intervention exposure resulted in decreases of over $\$ 8690$ per 6-month period for all participants compared with controls and \$15,998 for Medicaid participants. Given an annual enrollment of 216 patients (2014 average monthly enrollment = 18 ), we estimated that SafeMed was associated with gross annual savings of $\$ 8690 \times 216=\$ 1,877,040$. With estimated annual SafeMed program costs of $\$ 972,496$, we calculated an expected annual net savings of $\$ 904,544$ or a $\$ 4118$ net savings per SafeMed enrollee per 6-month period. If a health system used the SafeMed model to target only Medicaid enrollees, using similar cost assumptions, we estimate expected an annual net savings of $\$ 11,810$ per Medicaid SafeMed enrollee per 6-month period. Accountable care organizations might expect to achieve even greater savings if they could lower program costs by minimizing evaluation expenditures and building on existing system personnel and capacities.

Our study had a number of limitations. Most importantly, participation in the SafeMed program was not random, and there were several differences between SafeMed enrollees and controls. Thus, despite our rigorous quasi-experimental DID study design with concurrent controls, we cannot rule out unmeasured confounding. However, although DID models with only one pre-intervention and one post-intervention observation cannot control for differences in time trends in the SafeMed enrollees and controls, they do allow for control of permanent unobserved differences between the groups. Some residual selection bias could have contributed to the success of the intervention, particularly since some socially complex patients were excluded. However, diagnostic data were used for exclusions and behavioral health conditions are notoriously underreported. Only five patients with behavioral health conditions were excluded. Although we attempted to screen for homelessness early in the study, staff screening was found to be highly inaccurate and was discontinued. As a result, no patients were excluded as a result of homelessness. Moreover, exclusion criteria were applied equally to both participants and controls, which minimize selection bias.

However, non-random allocation of patients resulted in some differences between the intervention and control groups that may have diluted intervention impact on major outcomes. Control patients were older, with higher percent of white, more Medicare enrolled, and higher baseline rates of primary care use. Given that the intervention appeared to have its greatest impact through increasing primary care engagement, the control group may have gotten a similar benefit from their baseline higher levels of primary care engagement as did the intervention group only through the impact of the intervention. Thus, demonstrated program effect may have been diluted through unmeasured confounding related to between group differences in primary care engagement.

It is also possible that the study may have limited generalizability. The study recruited patients with high utilization within a single health care system in Memphis, TN, with above average readmission rates among a mostly underserved patient population. Thus, our results may not be broadly generalizable to other regions or populations with severe mental illness, but are likely to apply to the most typical super-utilizers in medically underserved areas and hotspot regions for readmissions. Positive impact for the SafeMed intervention was only found among Medicaid enrollees and may not apply to other insured populations with high baseline utilization of primary care services. Medicare patients may already benefit from other programs specifically designed to meet their needs. It is also possible that our study was underpowered to detect an effect for our smaller Medicare sample. Future research should further test whether primary care engagement mediates the effectiveness of interventions like SafeMed that seek to improve care transitions by increasing follow-up primary care visits. ${ }^{50,55,56}$

Long-term support for effective care transition programs for high-need, high-cost patients is a critical policy priority. Even though SafeMed was patient-centered and produced substantial cost reductions per enrollee, all savings accrued to Medicaid, while costs were borne by program partners. Thus, value-based payment reform is essential for the sustainability of effective care transition programs. Fortunately, CMS is aggressively shifting to payment approaches tied to value and quality. Our research indicates that state Medicaid programs can also promote high-value care by actively supporting evidence-based care transition models like SafeMed. Care transition models emphasizing strong interdisciplinary patient engagement and rapid primary care follow-up offer substantial promise for achieving simultaneous improvements in quality, outcomes, and costs among high-need, high-cost Medicaid patients.

Corresponding Author: James E. Bailey, MD; Center for Health System Improvement, University of Tennessee Health Science Center, Memphis, TN, USA (e-mail: jeb@uthsc.edu).

Author Contributions The authors gratefully acknowledge Patti Smith, MPH, for her editorial assistance; Karen Hopper, MD, Michelle Scroggins, FNP, Paula Bell, PharmD, Angel Jones, PharmD, Leigh Anne Keough, PharmD, Caprice Brown, RN, Bonnye Griffin, MSW, Cassandra Norwood, MSW, Patricia Wright, LPN, Brittney Willoughby, LPN, Justin Wright, CPT, Amanda Clayborne-Clark, CPT, Jill Connors, $\mathrm{PhD}$, Sarah Henning, MHSA, and Mansoor Shahid, MHA for their dedicated service to vulnerable patients in need; and most importantly, to the people served by the SafeMed program who helped us understand the care they need most. 
Funding The project described was supported by Grant Number ICIMS 331067-01-00 from the Department of Health and Human Services, Centers for Medicare \& Medicaid Services. The contents of this publication are solely the responsibility of the authors and do not necessarily represent the official views of the US Department of Health and Human Services or any of its agencies. In addition, this work was partially supported by the University of Tennessee Health Science Center and the Robert S. Pearce Endowed Chair in Internal Medicine.

\section{Compliance with Ethical Standards:}

Conflict of Interest: The authors declare that they do not have a conflict of interest.

\section{REFERENCES}

1. Cohen SB, Yu W. The concentration and persistence in the level of health expenditures over time: estimates for the U.S. population, 2008-2009. Statistical Brief \#354. Rockville, MD: Agency for Healthcare Research and Quality. 2014. Available at https://meps.ahrq.gov/data_files/publications/st354/stat354.pdf. Accessed 13 March 2019.

2. Jiang HJ, Weiss A, Barrett ML, Sheng M. Characteristics of hospital stays for super-utilizers by payer, 2012. HCUP Statistical Brief [Internet]. May 30, 2017; \#190. Available at: http://www.hcup-us.ahrq.gov/reports/statbriefs/sb190-Hospital-Stays-Super-Utilizers-Payer-2012.pdf Accessed 13 March 2019.

3. Health Affairs. Health Affairs Blog [Internet]. Bethesda, MD: Health Affairs. 2012 September 12 [cited 2019 March 13]. Available at: https://www. healthaffairs.org/do/10.1377/hblog20120921.023379/full/.

4. Robert Wood Johnson Foundation. Reducing hospital readmissions: a revolutionary approach to improving health care delivery. [Internet]. Princeton, NJ: RWJF; 2014 Feb 1 [cited March 13, 2019]. Available at: https://www.rwjf.org/en/library/articles-and-news/2014/02/improving-management-of-health-care-superutilizers.html. Accessed 13 March 2019.

5. Gawande A. The hot spotters: can we lower medical costs by giving the neediest patients better care? The New Yorker. January 2011. https:// www.newyorker.com/magazine/2011/01/24/the-hot-spotters. Accessed 13 March 2019.

6. Kaufman S, Ali N, DeFiglio V, Craig K, Brenner J. Early efforts to target and enroll high-risk diabetic patients into urban community-based programs. Health Promot Pract 2014;15(2 Suppl):62S-70S. doi: https://doi.org/10.1177/1524839914535776.

7. Vaida B. For super-utilizers, integrated care offers a new path. Health Aff (Millwood) 2017;36(3):394-7. doi: https://doi.org/10.1377/hlthaff.2017.0112.

8. Long $\mathbf{P}$, Abrams M, Milstein A, Anderson G, Lewis Apton K, Lund Dahlberg M, et al. Effective care for high-need patients: opportunities for improving outcomes, value, and health. Washington, DC: National Academy of Medicine, 2017.

9. Hong CS, Siegal AL, Ferris TG. Caring for high-need, high-cost patients: what makes for a successful care management program? Issue Brief (Commonw Fund) 2014;19:1-19. https://www.commonwealthfund.org/ publications/issue-briefs/2014/aug/caring-high-need-high-cost-patients-what-makes-successful-care. Accessed 13 March 2019.

10. Hong CS, Abrams MK, Ferris TG. Toward increased adoption of complex care management. N Engl J Med 2014;371(6):491-3. doi: https://doi. org/10.1056/NEJMp1401755.

11. Bray-Hall ST. Transitional care: focusing on patient-centered outcomes and simplicity. Ann Intern Med 2012;157(6):448-9. doi: https://doi.org/ 10.7326/0003-4819-157-6-201209180-00010.

12. Feltner C, Jones CD, Cene CW, Zheng ZJ, Sueta CA, CokerSchwimmer EJ, et al. Transitional care interventions to prevent readmissions for persons with heart failure: a systematic review and meta-analysis. Ann Intern Med 2014;160(11):774-84. doi: https://doi. org/10.7326/M14-0083.

13. Hayes SL, Salzberg CA, McCarthy D, Radley DC, Abrams MK, Shah T, et al. High-need, high-cost patients: who are they and how do they use health care? a population-based vomparison of demographics, health care use, and expenditures. Issue Brief (Commonw Fund) 2016;26:1-14

14. Joynt KE, Figueroa JF, Beaulieu N, Wild RC, Orav EJ, Jha AK. Segmenting high-cost Medicare patients into potentially actionable cohorts. Healthc (Amst) 2017;5(1-2):62-7. doi: https://doi.org/10. 1016/j.hjdsi.2016.11.002.
15. Coleman EA. Falling through the cracks: challenges and opportunities for improving transitional care for persons with continuous complex care needs. J Am Geriatr Soc 2003;51(4):549-55.

16. Coleman EA, Smith JD, Raha D, Min SJ. Posthospital medication discrepancies: prevalence and contributing factors. Arch Intern Med 2005;165(16):1842-7. doi: https://doi.org/10.1001/archinte.165.16.1842.

17. Forster AJ, Murff HJ, Peterson JF, Gandhi TK, Bates DW. The incidence and severity of adverse events affecting patients after discharge from the hospital. Ann Intern Med 2003;138(3):161-7.

18. Corbett CF, Setter SM, Daratha KB, Neumiller JJ, Wood LD. Nurse identified hospital to home medication discrepancies: implications for improving transitional care. Geriatr Nurs 2010;31(3):188-96. doi: https://doi.org/10.1016/j.gerinurse.2010.03.006.

19. Makaryus AN, Friedman EA. Patients' understanding of their treatment plans and diagnosis at discharge. Mayo Clin Proc 2005;80(8):991-4. doi: https://doi.org/10.4065/80.8.991.

20. Coleman EA, Parry C, Chalmers S, Min SJ. The care transitions intervention: results of a randomized controlled trial. Arch Intern Med 2006;166(17):1822-8. doi: https://doi.org/10.1001/archinte.166.17.1822.

21. Naylor MD, Brooten DA, Campbell RL, Maislin G, McCauley KM, Schwartz JS. Transitional care of older adults hospitalized with heart failure: a randomized, controlled trial. J Am Geriatr Soc 2004;52(5):67584. doi: https://doi.org/10.1111/j.1532-5415.2004.52202.x.

22. Kripalani S, Roumie CL, Dalal AK, Cawthon C, Businger A, Eden SK, et al. Effect of a pharmacist intervention on clinically important medication errors after hospital discharge: a randomized trial. Ann Intern Med 2012;157(1): 1-10. doi: https://doi.org/10.7326/0003-4819-157-1201207030-00003.

23. Walker DG, Aedo C, Albala C, Allen E, Dangour AD, Elbourne D, et al. Methods for economic evaluation of a factorial-design cluster randomised controlled trial of a nutrition supplement and an exercise programme among healthy older people living in Santiago, Chile: the CENEX study. BMC Health Serv Res 2009;9:85. https://doi.org/10.1186/1472-6963-9-85.

24. Kalista T, Lemay V, Cohen L. Postdischarge community pharmacistprovided home services for patients after hospitalization for heart failure. J Am Pharm Assoc (2003). 2015;55(4):438-42. doi: https://doi.org/10. 1331/JAPhA.2015.14235.

25. Phatak A, Prusi R, Ward B, Hansen LO, Williams MV, Vetter E, et al. Impact of pharmacist involvement in the transitional care of high-risk patients through medication reconciliation, medication education, and postdischarge call-backs (IPITCH Study). J Hosp Med 2016;11(1):39-44. doi: https://doi.org/10.1002/jhm.2493.

26. Williams MV, Li J, Hansen LO, Forth V, Budnitz T, Greenwald JL, et al. Project BOOST implementation: lessons learned. South Med J 2014;107(7):455-65. doi: https://doi.org/10.14423/SMJ. 0000000000000140.

27. Altfeld S, Pavie K, Rosenberg W, Shure I. Integrating care across settings: the Illinois Transitional Care Consortium's Bridge Model. Generations: Journal of the American Society on Aging; 2013 [cited 2017 June 2]. Available at: http://www.asaging.org/blog/integratingcare-across-settings-illinois-transitional-care-consortium\%E2\%80\%99sbridge-model. Accessed 12 March 2019.

28. Jack BW, Chetty VK, Anthony D, Greenwald JL, Sanchez GM, Johnson AE, et al. A reengineered hospital discharge program to decrease rehospitalization: a randomized trial. Ann Intern Med 2009; 150(3):178-87.

29. Bunting BA, Cranor CW. The Asheville Project: long-term clinical, humanistic, and economic outcomes of a community-based medication therapy management program for asthma. J Am Pharm Assoc (2003). 2006;46(2): 133-47.

30. Bailey JE, Surbhi S, Bell PC, Jones AM, Rashed S, Ugwueke Mo. SafeMed: using pharmacy technicians in a novel role as community health workers to improve transitions of care. J Am Pharm Assoc (2003) 2016;56(1):73-81. doi: https://doi.org/10.1016/j.japh.2015. 11.011 .

31. Harris LJ, Graetz I, Podila PS, Wan J, Waters TM, Bailey JE. Characteristics of hospital and emergency care super-utilizers with multiple chronic conditions. J Emerg Med 2016;50(4):e203-14. doi: https://doi.org/10.1016/j.jemermed.2015.09.002.

32. Health Resources Administration. HRSA Data Warehouse MUA Find: U.S. Department of Health \& Human Services; 2017 [cited 2017 June 9]. Available from: https://datawarehouse.hrsa.gov/tools/analyzers/muafind.aspx.

33. QSource. A regional call to action on transitions of care: Memphis: BSource; 2011; p 8.

34. Surbhi S, Munshi KD, Bell PC, Bailey JE. Drug therapy problems and medication discrepancies during care transitions in super-utilizers. J Am 
Pharm Assoc (2003). 2016;56(6):633-42 el. doi: https://doi.org/10. 1016/j.japh.2016.07.004.

35. Bailey JE, Binkley BL. Using the SafeMed model to improve transitions of care. Practice Transformation Series [Internet]. 2016; 2017(May 16). Available at: https://www.stepsforward.org/modules/safemed-transition-care. Accessed 12 March 2019

36. Bindman AB, Chattopadhyay A, Auerback GM. Interruptions in Medicaid coverage and risk for hospitalization for ambulatory caresensitive conditions. Ann Intern Med 2008;149(12):854-60.

37. Oster A, Bindman AB. Emergency department visits for ambulatory care sensitive conditions: insights into preventable hospitalizations. Med Care 2003;41(2):198-207. doi: https://doi.org/10.1097/01.MLR. $0000045021.70297 .9 \mathrm{~F}$.

38. National Quality Forum. Measures, Reports \& Tools; [cited 2017 July 23]. Available from: http://www.qualityforum.org/Measures_Reports_Tools. aspx. Accessed 12 March 2019

39. Choudhry NK, Shrank WH, Levin RL, Lee JL, Jan SA, Brookhart MA, et al. Measuring concurrent adherence to multiple related medications. Am J Manag Care 2009;15(7):457-64.

40. Agency for Healthcare Research and Quality. Prevention quality overall composite technical specifications, Prevention Quality Indicator 90 (PQI 90), AHRQ Quality Indicators ${ }^{\mathrm{TM}}$, Version 6.02016 May 31, 2017. Available at: www.qualityindicators.ahrq.gov/Downloads/Modules/PQI/V60ICD10/TechSpecs/PQI_90_Prevention_Quality_Overall_Composite.pdf. Accessed 12 March 2019.

41. Jencks SF, Williams MV, Coleman EA. Rehospitalizations among patients in the Medicare fee-for-service program. New Engl J Med 2009;360(14):1418-28. doi: https://doi.org/10.1056/NEJMsa0803563.

42. Research Data Assistance Center. Medicare-Medicaid dual eligibility code - January: ResDAC; 2016 [cited 2017 June 1]. Available at: https://www. resdac.org/cms-data/variables/Dual-Status-Code-occurs-12-times. Accessed 12 March 2019

43. ICD-9-CM Enhanced Charlson SAS code. Winnepeg, Canada: Manitoba Centre for Health Policy; 2006.

44. Riegel B, Naylor M, Stewart S, McMurray JJ, Rich MW. Interventions to prevent readmission for congestive heart failure. JAMA. 2004;291(23):2816; author reply -7. doi: https://doi.org/10.1001/jama.291.23.2816-a.

45. Bielaszka-DuVernay C. The 'GRACE' model: in-home assessments lead to better care for dual eligibles. Health Aff (Millwood) 2011;30(3):431-4. doi: https://doi.org/10.1377/hlthaff.2011.0043.

46. Kangovi S, Mitra N, Grande D, White ML, McCollum S, Sellman J, et al. Patient-centered community health worker intervention to improve posthospital outcomes: a randomized clinical trial. JAMA Intern Med
2014;174(4):535-43. doi: https://doi.org/10.1001/jamainternmed.2013. 14327.

47. Coburn KD, Marcantonio S, Lazansky R, Keller M, Davis N. Effect of a community-based nursing intervention on mortality in chronically ill older adults: a randomized controlled trial. PLoS Med 2012;9(7):e1001265. doi: https://doi.org/10.1371/journal.pmed.1001265.

48. Dorr DA, Wilcox AB, Brunker CP, Burdon RE, Donnelly SM. The effect of technology-supported, multidisease care management on the mortality and hospitalization of seniors. J Am Geriatr Soc 2008;56(12):2195-202. doi: https://doi.org/10.1111/j.1532-5415.2008.02005.x.

49. Durfee J, Johnson T, Batal H, Long J, Rinehart D, Everhart R, et al. The impact of tailored intervention services on charges and mortality for adult super-utilizers. Healthc (Amst). 2017. doi: https://doi.org/10. 1016/j.hjdsi.2017.08.004.

50. Jackson BM, Gutierrez ML, Relyea GE, Carlton EL, Ahn S, Binkley BL, et al. Unmet primary care needs in diabetic patients with multimorbidity in a medically underserved area. Health Serv Res Manag Epidemiol 2017;4:2333392817702760. doi: https://doi.org/10.1177/ 2333392817702760.

51. Raven MC, Kushel M, Ko MJ, Penko J, Bindman AB. The Effectiveness of emergency department visit reduction programs: a systematic review. Ann Emerg Med 2016;68(4):467-83 e15.doi: https://doi.org/10.1016/j. annemergmed.2016.04.015.

52. Jackson C, Shahsahebi M, Wedlake T, DuBard CA. Timeliness of outpatient follow-up: an evidence-based approach for planning after hospital discharge. Ann Fam Med 2015;13(2):115-22. doi: https://doi. org/10.1370/afm. 1753.

53. Eaddy MT, Cook CL, O'Day K, Burch SP, Cantrell CR. How patient costsharing trends affect adherence and outcomes: a literature review. P T 2012;37(1):45-55.

54. Roemer MI, Hopkins CE, Carr L, Gartside F. Copayments for ambulatory care: penny-wise and pound-foolish. Med Care 1975;13(6):457-66.

55. Blewett LA, Johnson PJ, Lee B, Scal PB. When a usual source of care and usual provider matter: adult prevention and screening services. J Gen Intern Med 2008;23:1354-60.

56. Ivey SL, Shortell SM, Rodriquez HP, Wang YE. Patient engagement in ACO practices and patient-reported outcomes among adults with co-occurring chronic disease and mental health conditions. Med Care 2018;56(7):551-56.

Publisher's Note Springer Nature remains neutral with regard to jurisdictional claims in published maps and institutional affiliations. 